\title{
HISTORICAL ANALYSIS AND IN-SITU INSPECTIONS OF A CULTURAL HERITAGE MASONRY BUILDING
}

\author{
A. DE ANGELIS ${ }^{1 *}$, F. SANTAMATO ${ }^{1}$, G. MADDALONI ${ }^{1}$, L. DE FILIPPIS ${ }^{2}$ AND M.R. \\ PECCE ${ }^{1}$ \\ ${ }^{1}$ Department of Engineering, University of Sannio \\ Piazza Roma, 21, 82100 Benevento, Italy \\ e-mail: \{adeangelis; francesco.santamato; giuseppe.maddaloni; pecce\}@unisannio.it \\ ${ }^{2}$ INAF - National Institute of Astrophysics \\ Salita Moiariello, 16 -80131 - Napoli \\ email: ldefilip@na.astro.it
}

Keywords: Historical Structure, Masonry, Historical notes, Non-Destructive Inspection

\begin{abstract}
Recent seismic events that hit the Centre Italy have highlighted the high vulnerability of the historical and architectonical heritage that is the richness of the country, pointing out once again the difficulty of the assessment of monumental buildings such as churches or historical palaces, due to their uniqueness, the absence of a design, the limitation of invasive in situ tests, but the importance of the knowledge to understand the seismic behavior more than the static analysis under the gravitational loads. In the present paper the knowledge procedure is framed considering the case study of an important nineteenth century astronomical observatory, constructed in 1816-1819. The building, located in Naples, in the southern of Italy, classified by the Italian code as an area of medium seismic hazard, is analyzed by the use of integrated investigation activities such as coring, flat jack tests, georadar to obtain all the information due to the variability of the materials and the influence of previous alterations and repairs, that are data all necessary to develop a reliable model.
\end{abstract}

\section{INTRODUCTION}

Historic and monumental constructions are the most important part of the cultural heritage of a Country and it is very important to protect those structures since they have an inestimable artistic value but also because they are open to the large assemble of people. In Italy the protection of the historical heritage against seismic hazard is paramount and requires the definition of reliable models able to represent the actual architectural, constructional and structural configuration. Thus, a preliminary diagnostic phase through geometrical surveys, photographic documentation, mapping of materials and construction techniques, decay pattern surveys play an important role for the collection of all data as extensively documented by scientific literature $[1,2,3,4]$. This phase of knowledge is particularly difficult because the historical constructions are always quite singular cases for which the same investigation plan cannot be applied, therefore the first step is to tailor it.

It is also worth to underline that during their life historic structures have experienced many 
actions and earthquake loads that contributed to cause a non-stopping, gradual transformation of the structure [5]. Another challenging task, closely linked to the history is the understanding of the design concepts and construction technique. Their knowledge could provide precious empirical information for the analysis and the possibility of applying conventional methods of modelling.

Therefore in order to well proceed in the assessment of an historical building, the first step is the attainment of a sound knowledge of the erection history to individuate the technique and materials used. With this perspective and aiming at the seismic protection of the building, this paper deals with the knowledge and investigation phases of an important nineteenth century astronomical observatory, constructed in the period 1816-1819, that is "the Astronomical Observatory of Capodimonte", located on a hill in Naples. The diagnosis phase was carried out through survey practices and not destructive tests such as geometrical and architectonical survey, cracking outline survey and analysis, semi-destructive tests, including essays and in situ single and double jacks tests for the mechanical characterization of materials. Actually, this diagnostic phase was preceded by a historical research in libraries and archives of documents related to the building's design and construction phases; the main aim is to interpret the historical notices in order to confirm the hypothesis on the masonry morphological and structural features of the monumental building set up based on the in situ investigation. In particular the importance of historical study and non-destructive investigations emerged clearly for the identification of the structure.
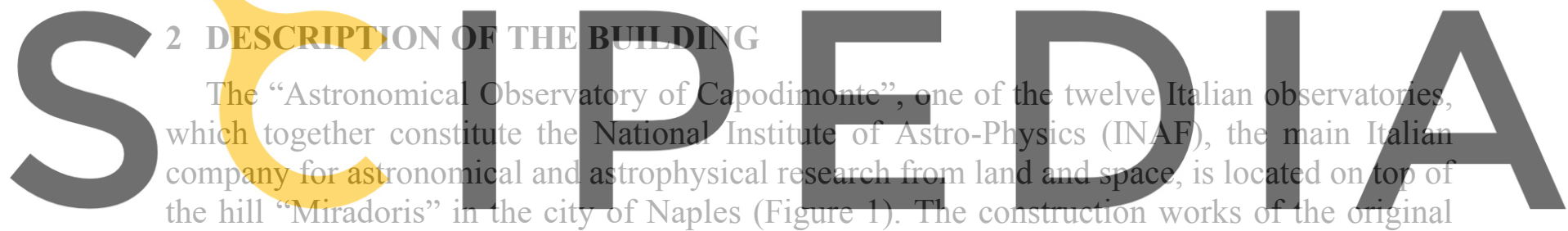
structure were promoted by Gioacchino Murat in 1812 but the structure was inaugurated thank

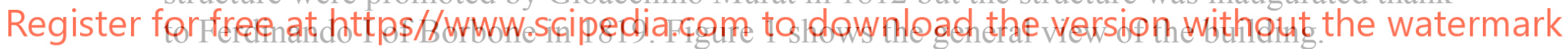
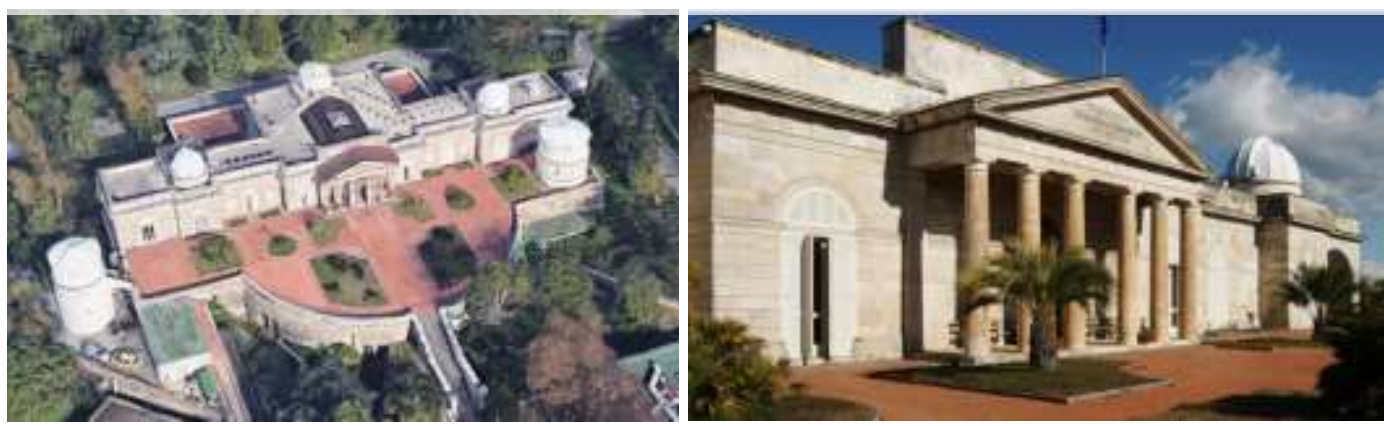

Figure 1: General view of the Astronomical Observatory of Capodimonte in Naples.

As a preliminary step, the complexity of the building required to get hold of a detailed knowledge of its geometry. Therefore, a complete in-situ inspection was carried out for understanding the organization of the structure. The plan layout of the ground floor of the astronomical observatory is reported in Figure 2. The building was realized using tuff (natural 
volcanic stone) masonry typical of the Italian region where is located. The plan has an elongated rectangular shape and approximately its dimensions are $65 \mathrm{~m} \times 20 \mathrm{~m}$. The construction has two stories; both the underground floor and the ground floor are approximately $4.0 \mathrm{~m} \mathrm{high}$. The thickness of the walls varies between $1.00-1.55 \mathrm{~m}$ at the underground floor, where it was not always possible to do the measure, and 0.50-1.00 at the ground floor. A particular feature of this building is due to the presence of a heavy stone cladding whose thickness equal to $25 \mathrm{~cm}$ was measured by means of a hole. This aspect is particularly important in a seismic analysis as it behaves as an additional mass.

The main entrance to the building is preceded by a pronaos surmounted by an architrave, the tympanum and other classical elements of the Greek temple architecture. In the building it is possible to recognize three main blocks: a central square block and two rectangular lateral blocks. The main rectangular room (central atrium) is characterized by two lines of marble columns and it is covered by a barrel vault with a glass skylight. Also, the lateral zones adjacent to the central atrium, are covered by barrel vaults or hemispherical dome, except the last rooms at the two ends that were added in 1935 using the same stone for masonry while the floor was realized by iron beams and clay tiles.
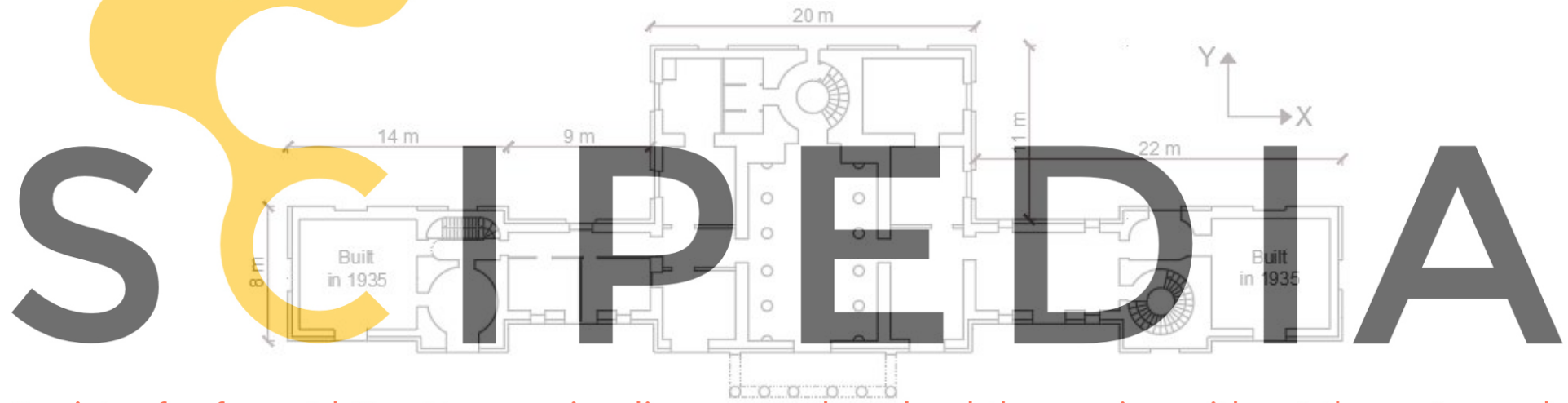

Register for free at https//www.scipedia.com to download, the version without the watermark

Figure 2: Pian layout of the ground fioor.

\section{HISTORICAL NOTES}

The historical reconstruction is necessary to understand the phases and techniques of erections. Referring to an historical document found in the building archive named "Ragguaglio del reale Osservatorio di Napoli eretto sulla Collina di Capodimonte", it is clear how the first design ideas were different and the construction of the entire building was troubled changing also during the works.

A conceptual design by Stefano Gasse, dated June 1812, included a facade similar to a classical temple with a monumental entrance formed by a tetrastyle pronaos which was reached by a staircase. Consulting other historical documents, it seems valid the hypothesis that the works corresponding to this project, reported in Figure 3 a, together with the coin celebrating the start of the work, were partially realized. In particular, the external and internal circles and the lateral wings may have been completed (the western one also completed with travertine cladding). 

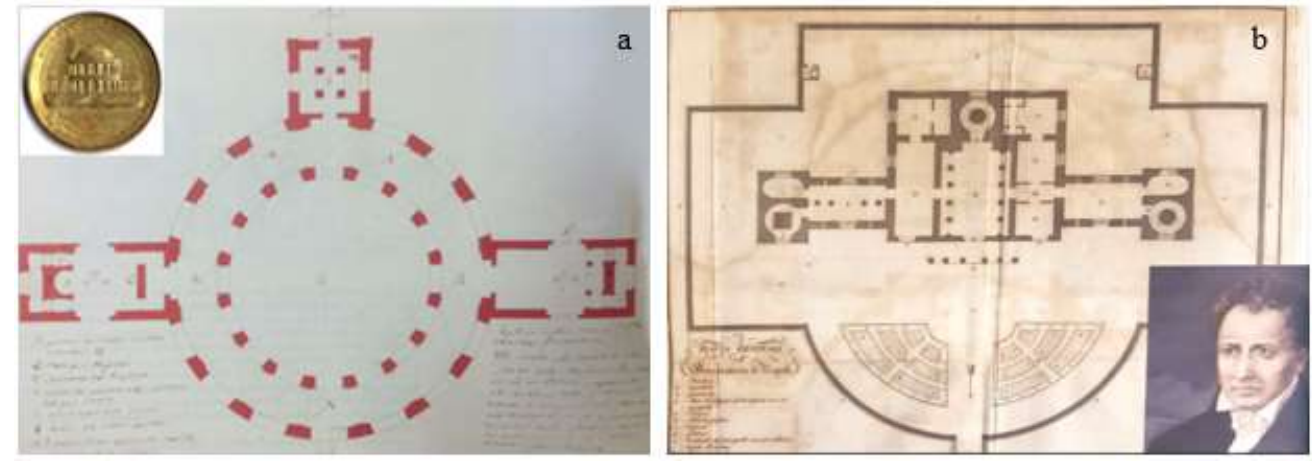

Figure 3: a) First project designed by Stefano Gasse in June 1812; b) Design of the built building.

However, the work was not completed for political and artistic reasons which led to a substantial change in the shape of the central part. The final design for the central part is that shown in Figure 3b. Therefore, it could be assumed that the plan of the ground floor of the historical building was founded on the plan envisaged by the project shown in Figure 3, but with the execution of "demolitions and excavations", as written in the historical documents, to support the walls and columns on appropriate underground walls. Unfortunately, the underground plan is not completely accessible, especially the central room, that was completely changed during the work, is closed along the perimeter. However, the considerations above

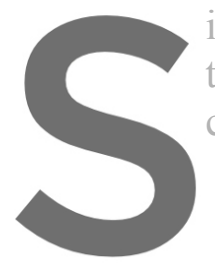
introduced find partial the realization of an Au central part of the build
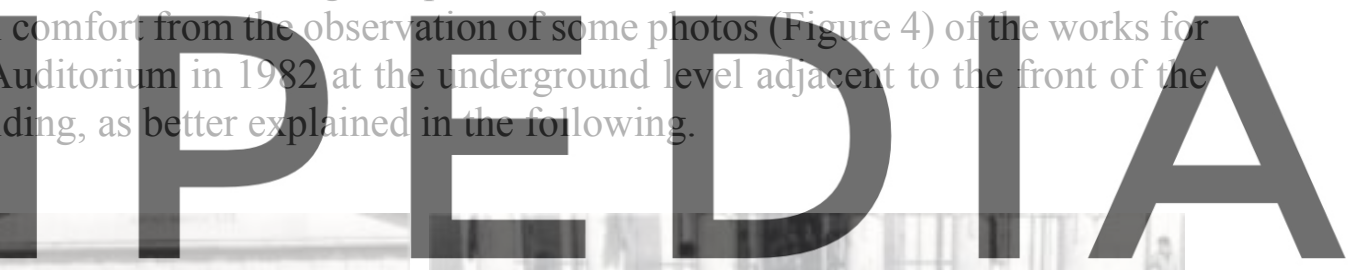

Register for free at https//www.scipedia.com to download the version without the watermark
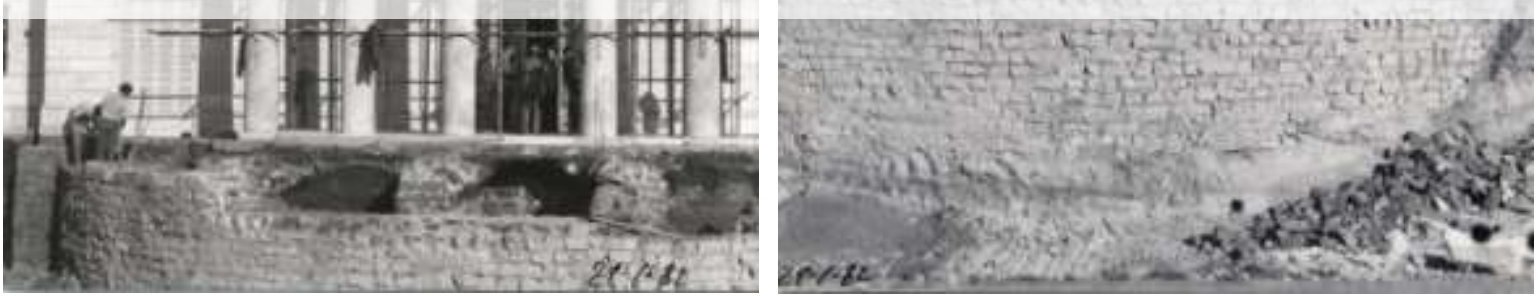

Figure 4: Works for the realization of the Auditorium in 1982.

In fact, from the photos it is clear that the external circumference and the radial corridors surmounted by main and secondary arches, in accordance with the project of Figure $3 \mathrm{a}$, had actually been constructed at the level currently buried in the square in front of it. Figure 5 shows the overlap of the current plan of building and the project designed by Stefano Gasse, suitably scaled considering the palm-meter conversion. This hypothesis is not surely confirmed underlining the great difficulties related to the identification of the structure of the underground 
level, that is of paramount importance for the structural analysis especially under seismic actions.

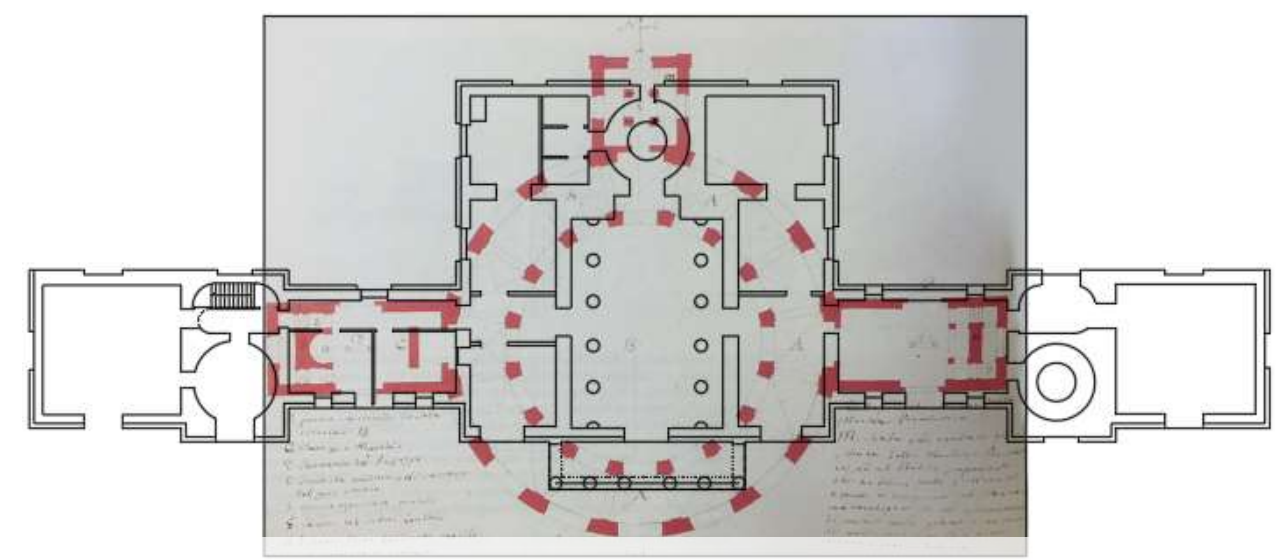

Figure 5: Overlap of the currently plan of the historical building and the project designed by Stefano Gasse.

The building was completed in 1819 but it has undergone some changes during the time especially when two rooms on two extreme sides in the longitudinal direction were realized in 1935 (Figure 3a and Figure 6), as written in other documents. Albeit the new parts were designed to be integrated in the same style of the original building they can be distinguished by the presence of a coating and a cornice in mortar and not in natural stone as for the ancient construction. Furthernore, the connection of the of the original end rooms changing the door pos visible in the original pling ig ositions and reinoving a larg
pported a telescope.
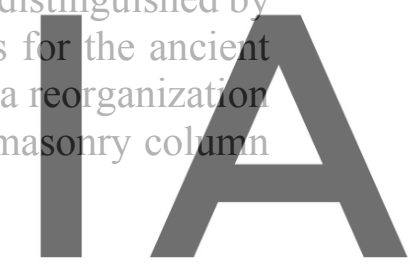

Register for free at https//www.scipedia.com to download the version without the watermark
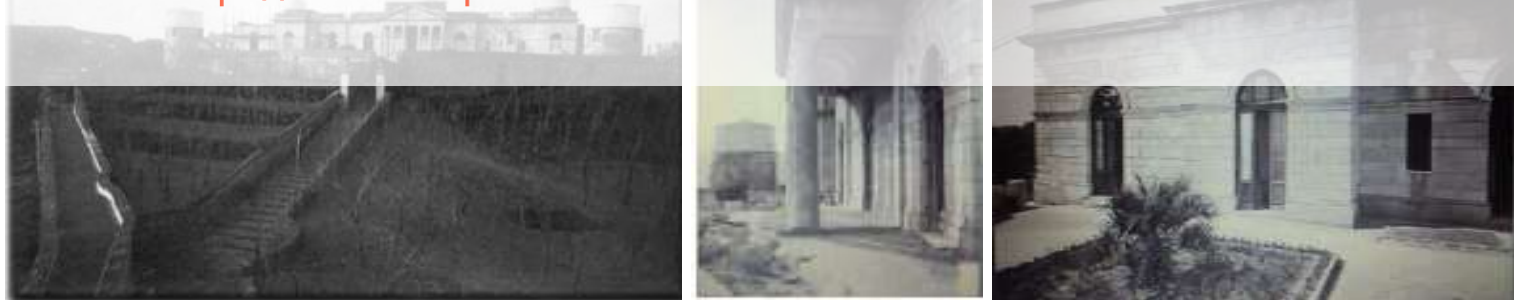

Figure 6: Enlargement work of the building in 1935

Further interventions were realized over the time along the perimeter with the construction of two buildings separated by a joint which were built by emptying the soil contained in the boundary wall of the courtyard in front and behind the observatory. Figure 7 show a complete layout of the underground level of the building including the boundary wall, the auditorium built in 1982 and the library built in 1990 .

Probably the soil contained between the basement of the building and the surrounding boundary wall was a carryover soil in 1819 after the conclusions of the original works, since the first 
design of the monumental building elaborated by Stefano Gasse provided that the entrance was at the level of the currently underground floor (see the coin in Figure 3a).

Nevertheless the real configuration of the basement, where the rooms with filling in the plan of Figure 7 are not accessible is still uncertain; in fact some zones as the central atrium, visible from the photo in Figure 8 taken during the construction of the auditorium, probably are empty while others as the side areas of the atrium are presumed to be full of soil because after the realization of some structural elements in shaped excavation the soil wasn't removed.
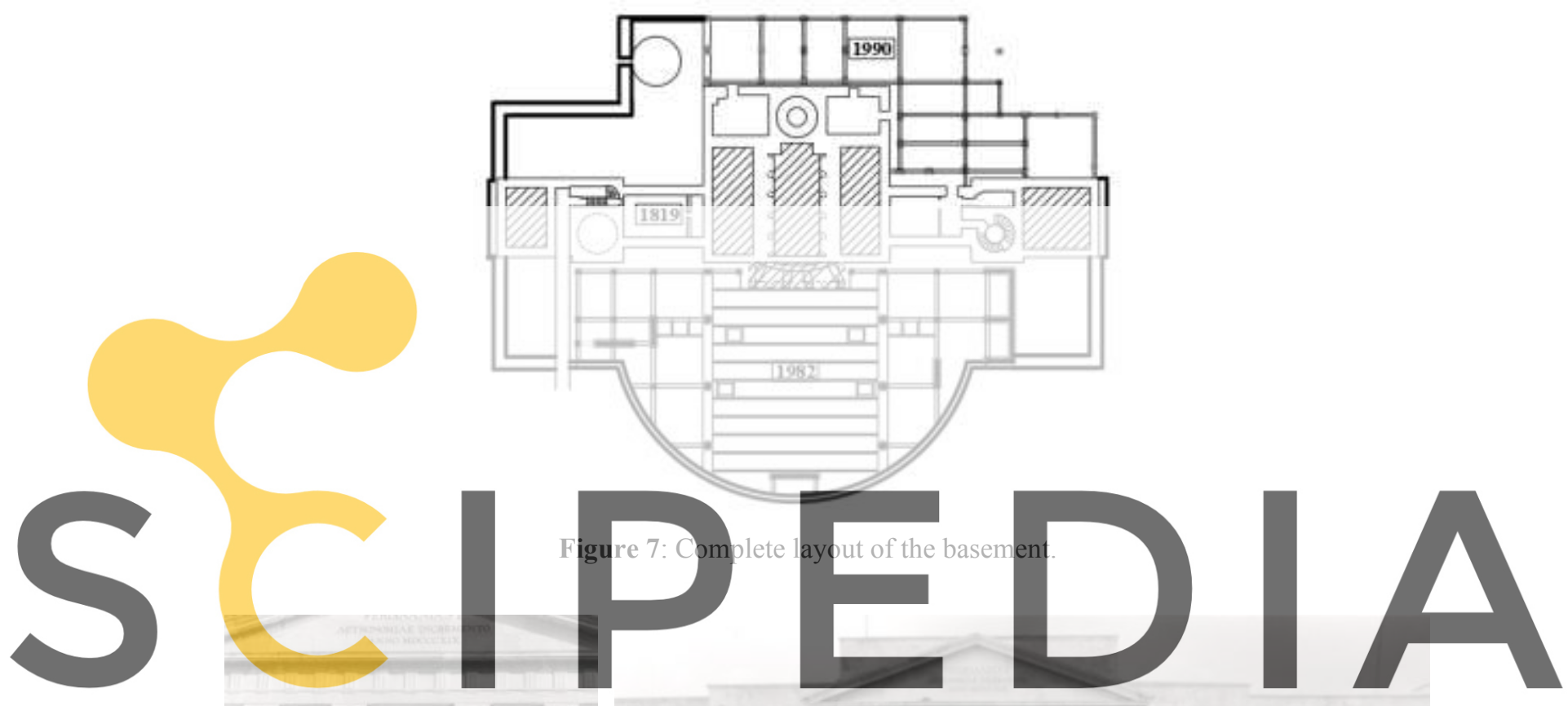

Register for free at https//www.scipedia.com to download the version without the watermark
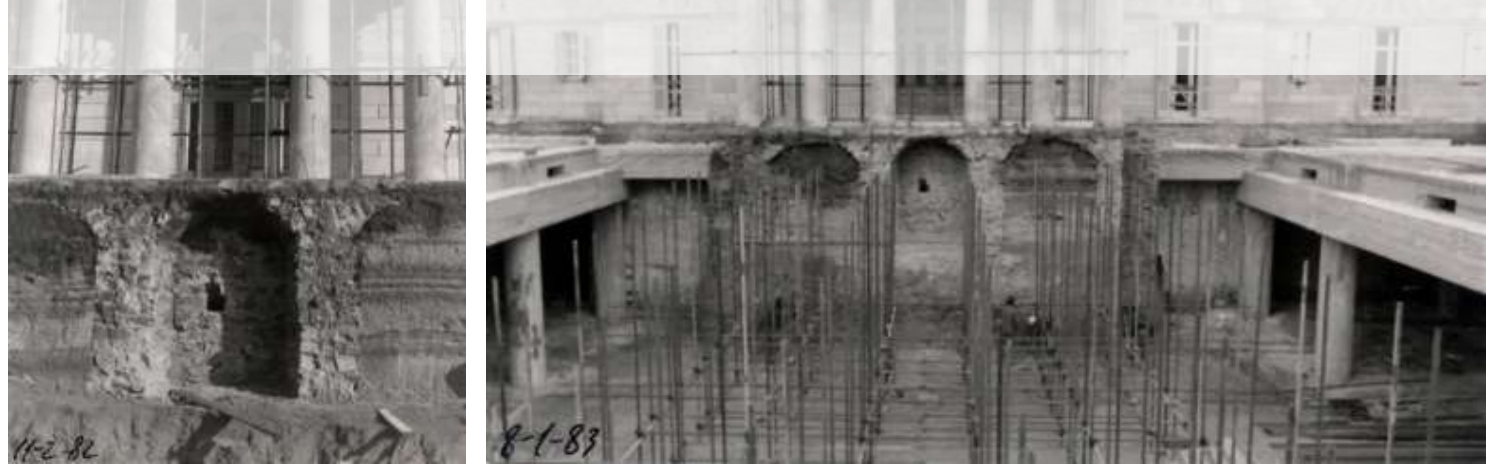

Figure 8: Photos of the working construction of Auditorium in 1982.

\subsection{Geo-radar investigation}

Since the distribution of the underground layout is still uncertain, a survey was carried out by means of a georadar, to obtain further information on the inaccessible internal environments with the aim of validating the hypotheses bases on documents and photos. The RADAR 
technique was developed in geophysical field for the study of the soil but it is currently employed successfully in archaeological investigations and new applications are even available for investigation on the foundations of buildings. The technique seems from one hand to be most promising, from the other it still needs of further studies and researches [6]. The method is based on the propagation of short electromagnetic impulses, which are transmitted into the building material using a dipole antenna, composed by an emitter and an acquisition unit. The impulses are reflected at interfaces between materials with different dielectric properties, i.e. at the surface and backside of walls, at detachments, voids, etc. The possibility to assess in depth the investigated structure depends on the frequency of the equipment: antenna with high frequency ( 2 or $5 \mathrm{GHz}$ ) is recommended for detailed analysis of the external layers of the composite structures, ensuring the propagation of electromagnetic impulses with short wavelength. On the contrary, antenna with low frequency (i.e. $600 \mathrm{MHz}$ ) generates long wavelength, indicated for characterizing large structures, but not always able to guarantee an appreciable resolution [7].

In this case the onsite investigation of the building was supported by high frequency radar scanning. The sections investigated, concentrated mainly in the central atrium area are shown in Figure 9.
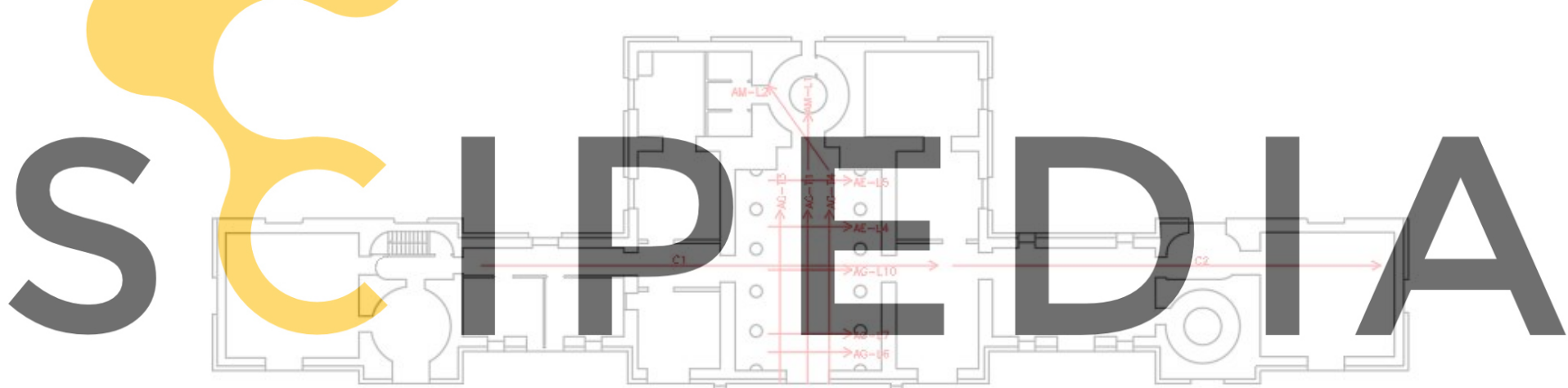

Register for free at https//www.scipedia.com to download the version without the watermark

Figure 9: Section investigated by georadar.

Only the most important results produced as radargrams, i.e. grey scale intensity charts giving the position of the antenna against the travel time, are reported. The radargram acquired along the corridor (Figure 10 and Figure 11) in the longitudinal direction gives a lot of information about the presence of walls, vaults and the detection of the fully and empty zones of the underground level. For the analysis of the results it should be considered that the small waves continuous along the depth with a hyperbolic shape correspond to a presence of a wall instead small hyperbolic waves at variable depths should correspond to the presence of a vault. The areas where the response is characterized by the absence of reflections can be considered fully of soil, while all areas where there is a very dense set of points can be considered empty.

The interpretation of the radargrams in the transversal direction is more challenging as the profiles are much shorter. In detail, for example, the radar profile AG-T1 (Figure 12) shows an initial area with quite regular hyperbolical reflections at variable depths, probably due to presence of a vault. Right after, from the middle to the end of the radargram reflections due to 
voids can be observed. Instead in the middle part of the radargram AM-L1, hyperbolic waves continuous in height are shown suggesting the presence of walls while the reflections at the end of the radargram are indicative of the continuation of the circular column at the stairwell up to the basement. It should be noted that despite the analysis of historical documents, the execution of the surveys and investigations also by means of georadar was important.

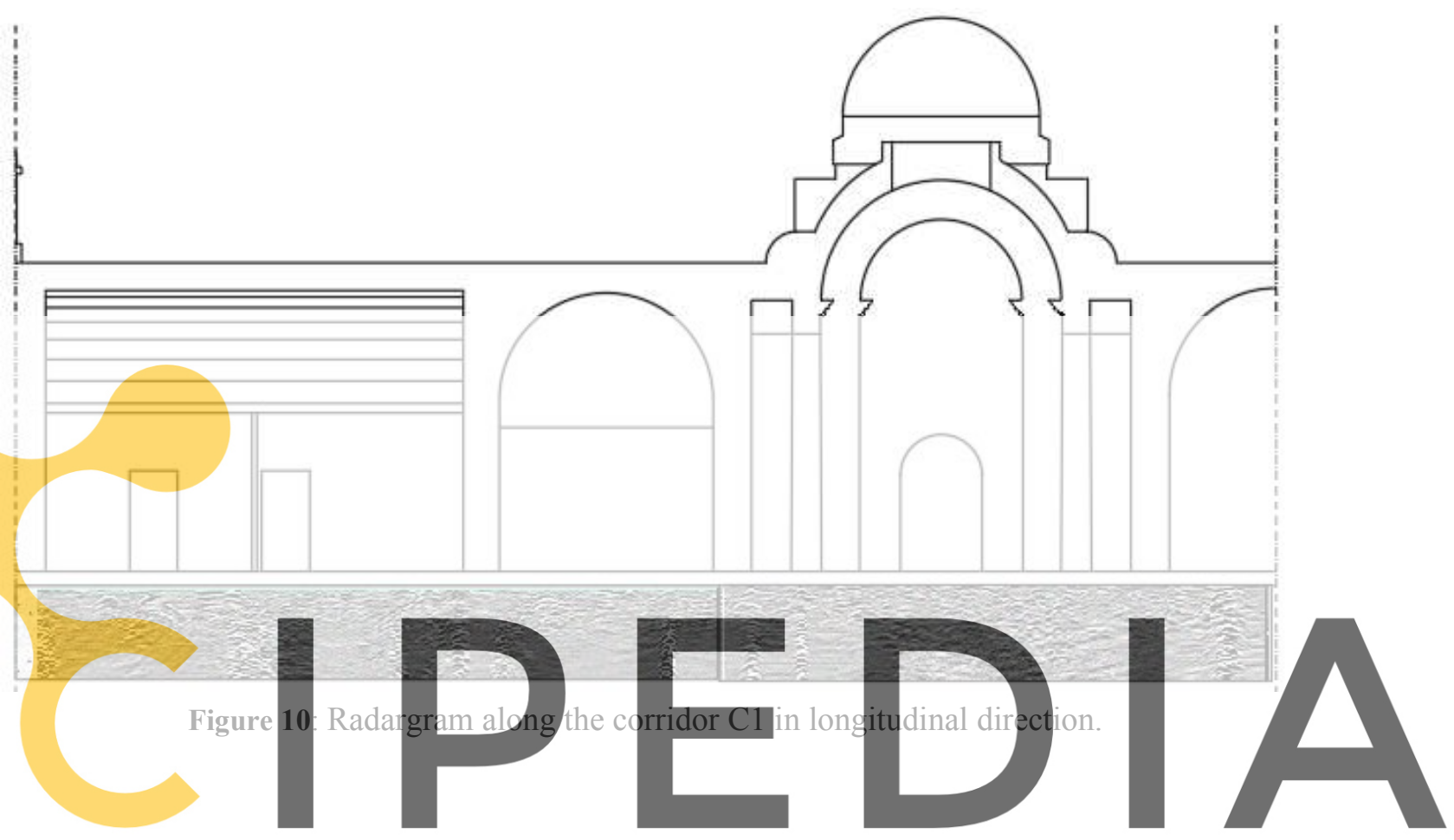

Register for free at https//www.scipedia.com to download the version without the watermark

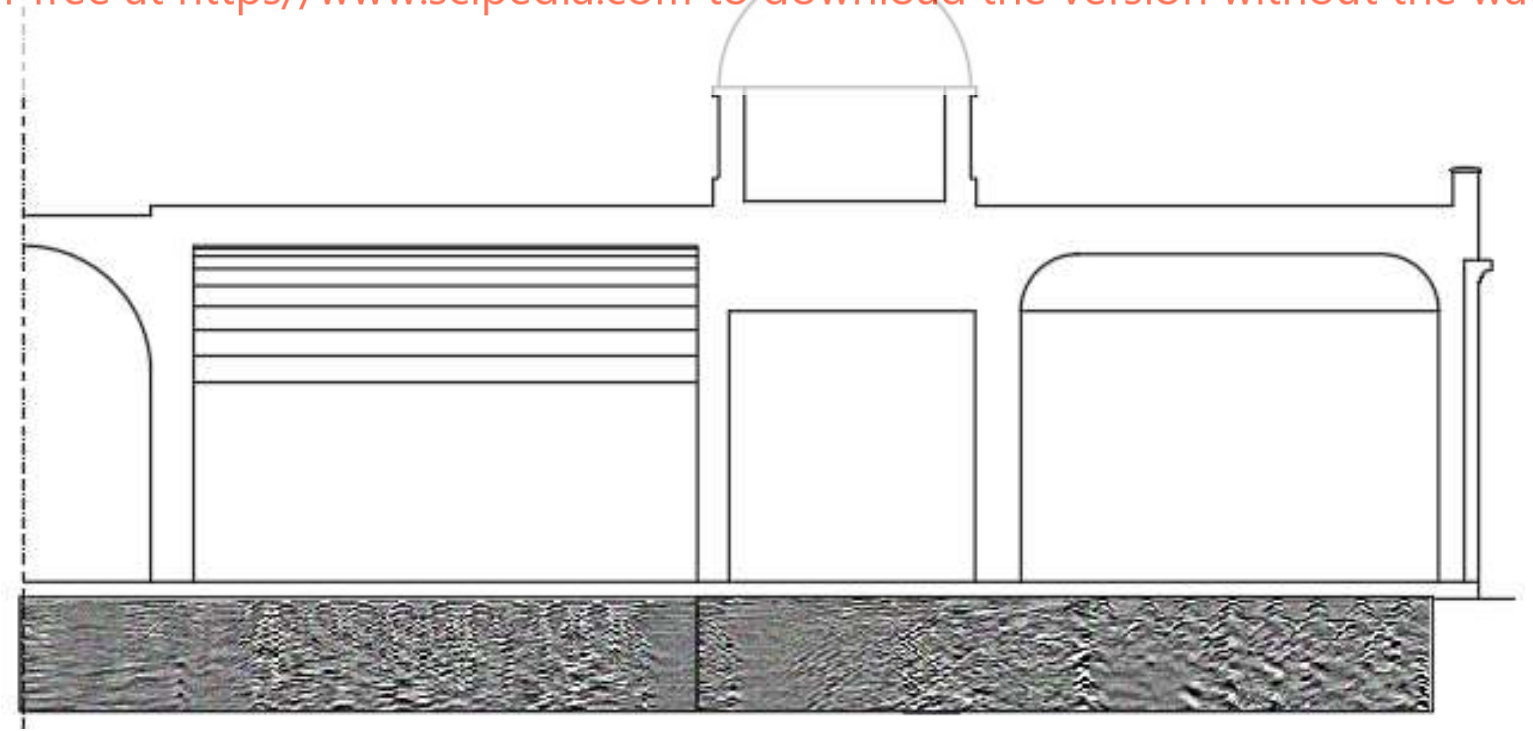

Figure 11: Radargram along the corridor $\mathrm{C} 2$ in longitudinal direction. 

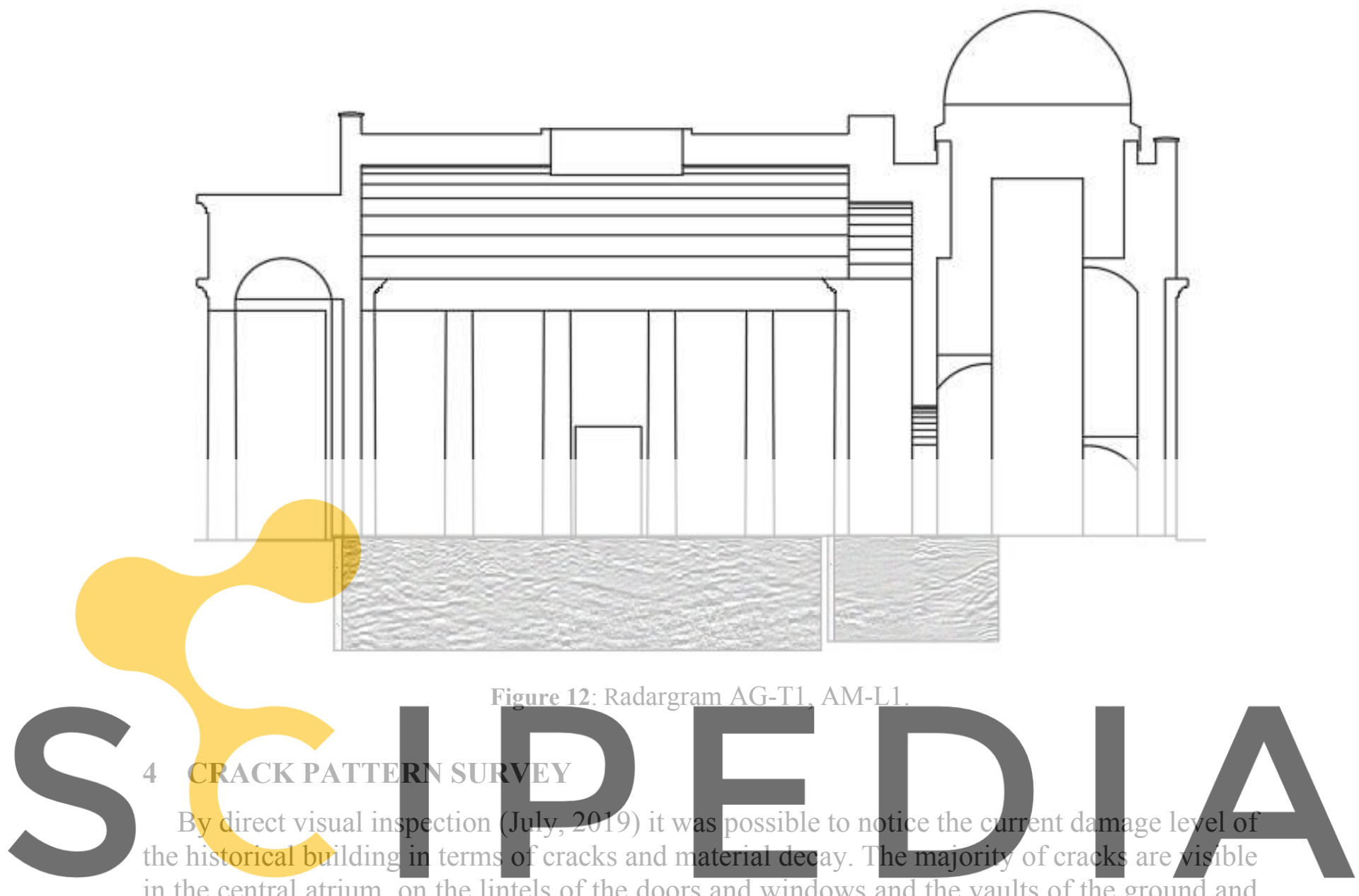
in the central atrium, on the lintels of the doors and windows and the vaults of the ground and

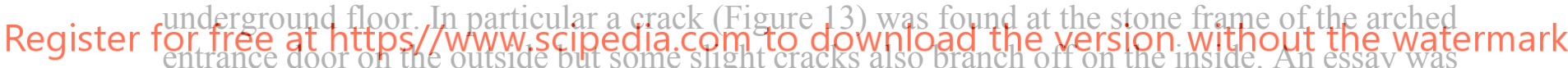
entrance door that make up the vault and affects the entire thickness of the wall. The crack is probably a local phenomenon due to the tension stresses at the intrados of arch key.
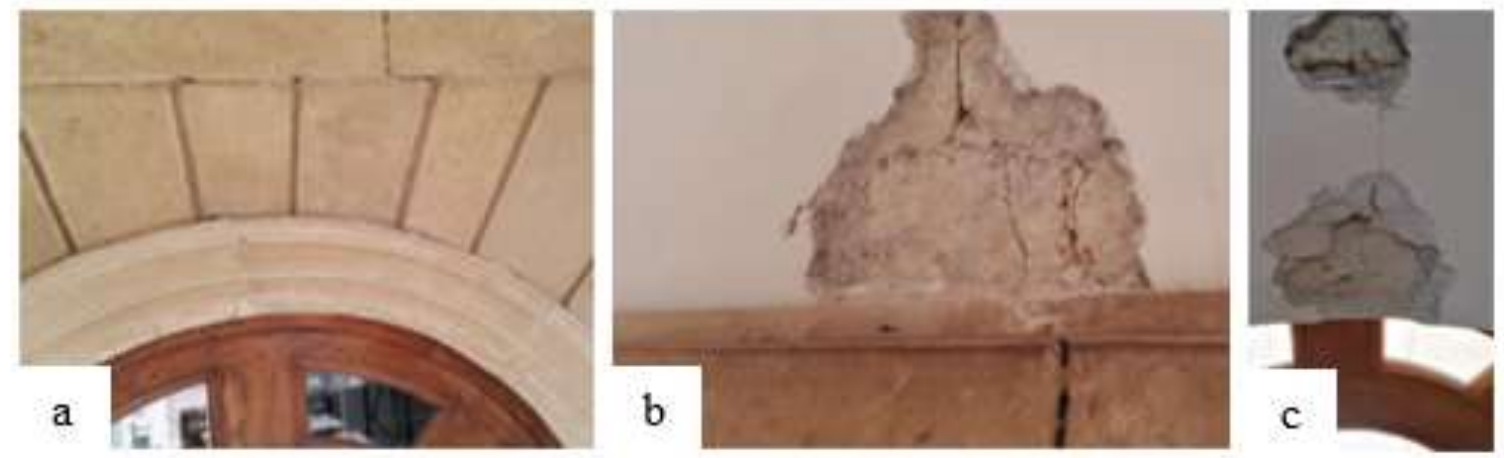

Figure 13: a) Crack at the stone arch of the entrance door; b) external essay; c) internal essay. 
Another area affected by widespread cracks is that in the back side of the building where there is a spiral staircase with a central circular column that allows access to the roof.

The upper part of the spiral staircase is closed by a vault which has a lot of cracks (Figure 14 a), typically visible along the key of the vault where the maximum tension stress occurs. In fact, when the plaster was removed for an area of about $30 \mathrm{~cm} \mathrm{x} 30 \mathrm{~cm}$ and a hole was realized through the thickness of the vault, it resulted made by one red brick $4 \mathrm{~cm}$ thick, that is a very thin structure sensible to bending effects. Another crack was visible in the middle of the entrance to the spiral staircase, therefore it was investigated removing the plaster (Figure 14b). It was observed that the entrance was realized without a stone or wood lintel even it is approximatively plane and not really an arch, thus the crack is due to bending effects.

Other widespread cracks due to the absence of lintels were found at all the openings (doors and windows) of the rooms of the building (Figure $14 \mathrm{c}$ ) while slight cracks were found at the barrel vaults covering some rooms (Figure $14 \mathrm{~d}$ ). All the cracks appear as local phenomena due to the low strength of the masonry in tension and degradation of the mortar but they don't indicate a local or global failure mechanism.

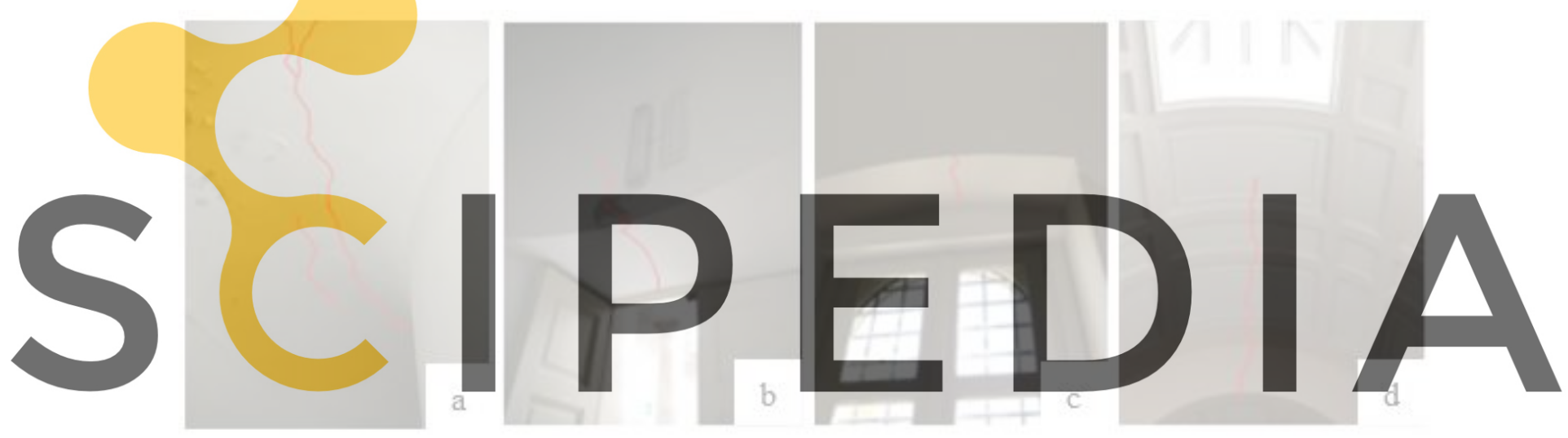

Finally, a vertical crack is located at the midspan of the stone lintel of the pronaos (Figure 15 a) that is actually shored up. An assay was performed at the crack on the internal side of the pronaos to check the stones of the vault that is supported by the stone lintel (Figure $15 \mathrm{~b}$ ). The tuff block $28 \mathrm{~cm}$ thick used to realize the vault resulted not cracked confirming that the damage regards only the stone lintel and it is caused by the tensile stresses in bending together with the stone degradation (Figure $15 \mathrm{c}$ ) due to uncorrect raining water disposal. 

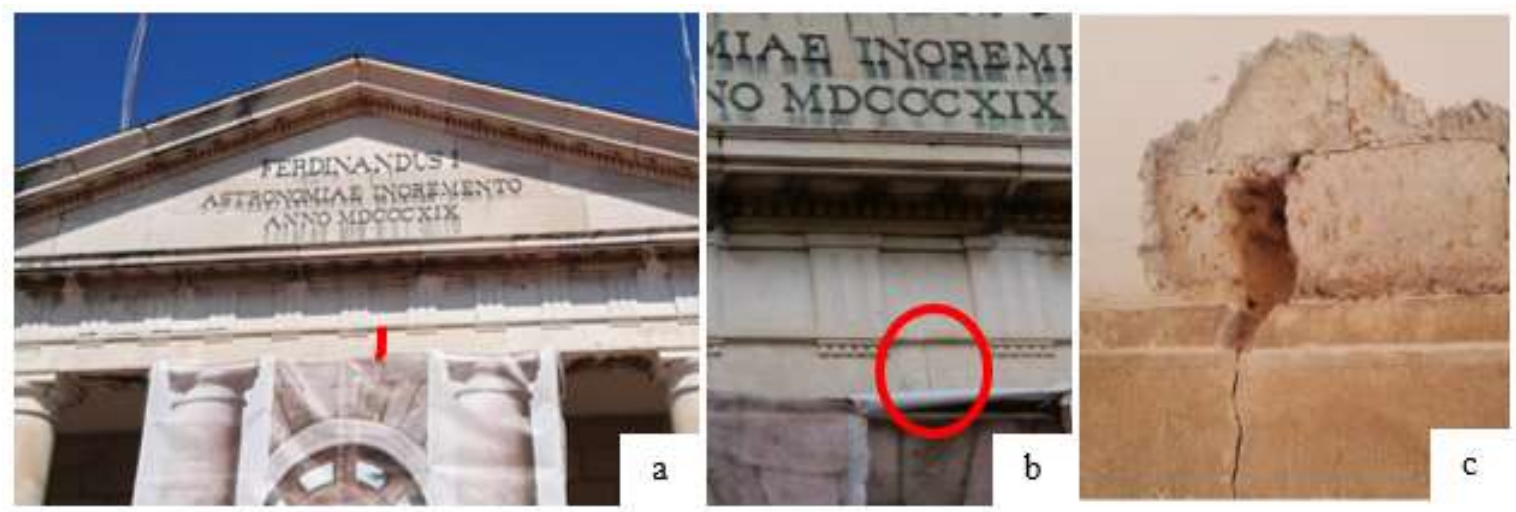

Figure 15: Crack at the midspan of the stone lintel (a-b); c) essay at the internal side.

\section{IN SITU SEMI-DESTRUCTIVE EXPERIMENTAL TESTS}

The diagnostic tests are usually divided in two categories: qualitative and quantitative tests. Qualitative tests, as the non destructive ones [8] previously introduced, provide generic information and cannot be directly related to the physical and mechanical parameters of the materials forming the structures. On the contrary, quantitative results can be obtained by minor destructive or destructive diagnostic tests ensuring a deeper level of knowledge of the structure characteristics. In this case three tests with flat jacks were carried out; in particular a single flat jack test was performed to ensure the determination of the actual compression stresses in the masonry walls, useful for validating a numerical model.

The test was carried out by introducing a thin flat-jack into the mortar layer. A compression stress of approximately $0.25 \mathrm{MPa}$ was obtained. Instead, two double flat jacks were performed to identify the mechanical characteristics, one in the more ancient part of the building and one at the extreme side rooms constructed in 1935. For the main original part of the building, the Young modulus $\mathrm{E}$ and the Poisson ratio $v$ resulted equal to $905 \mathrm{MPa}$ and 0.2 respectively whereas the volumetric weight is $\rho=14 \mathrm{kN} / \mathrm{m}^{3}$ and the masonry average compressive strength is $\mathrm{f}_{\mathrm{m}}=2 \mathrm{MPa}$. Instead for the newer zones, the Young modulus $\mathrm{E}$ and the average compressive strength $\mathrm{f}_{\mathrm{m}}$ resulted equal to $450 \mathrm{MPa}$ and $1.5 \mathrm{MPa}$, respectively.

It worth to note the values related to the old part of the building are in good agreement with the results from laboratory tests on Neapolitan yellow tuff masonry [9] showing a mean compressive strength equal to $2.78 \mathrm{MP}$ and an experimental Young's modulus varied between $630 \mathrm{MPa}$ and $2943 \mathrm{MPa}$. Instead, the values related to the new part of the building are at least $50 \%$ lower than the previous ones. The results evidenced the higher quality of the material and hand-making of the more ancient construction conversely to the idea that new structure could have better performances.

\section{CONCLUSIONS}

The procedure of knowledge of the case study of the "Astronomical Observatory of Capodimonte", located in Naples, is useful to underline the importance of an accurate historical investigation for the structural identification of monumental constructions also to guide the insitu test campaign. In fact, the hypothesis on the masonry morphological and structural features of the monumental building were necessary to plan the type of tests and their location. 
The geometrical survey together with a georadar investigation allowed to better assess the organization of the underground floor not completely accessible. However, the mechanical properties of the materials have to be necessarily recognized through in situ semi-destructive tests like flat jacks, because some types of stone realized in various periods can give different resistance as in the case study. The visual inspection with the survey of the crack distribution in masonry can give a reliable framework of local or global mechanisms due to the low strength of the material in tension.

The investigation described in this paper was the first necessary step for the reliable structural analysis of the building that is in progress confirming the importance of the detailed identification of the underground floor.

Acknowledgements. The work was carried out within the framework of the PON Research and Innovation 2014-2020, Axis I-Investments in Human Capital, MIUR notice AIM-“International Attraction and Mobility"-Line 1, Project: AIM 1823125-3 - Cultural Heritage. The authors are also grateful to Dr. Raffaele Zollo for his help with the georadar test.

\section{REFERENCES}

[1] Binda, L., Saisi, A., Tiraboschi, C. Investigation procedures for the diagnosis of historic masonries, Construction and Building Materials, (2000) 14(4), pp. 199-233.

[2] Roca, P., González, J. L., 2001. Morphology, Structure and History. The case study of the upper flying arches of Mallorca Cathedral. International Millenium Congresso More than two thousand years in the history of architecture, Ib 22, Paris: ICOMOS 2001

[3] Ramos, L., Casarin, F., Algeri, C., Lourenco, P.B., Modena C. Investigation techniques carried out on the Qutb Minar, New Delhi, India. In Proceedings of the 5th international seminar on structural analysis of historical constructions. New Delhi, India, November 68, 2006.

[4] Bosiljkov, V., Uranjek, M., Žarnić, R., Bokan-Bosiljkov, V. An integrated diagnostic approach for the assessment of historic masonry structures. J Cultural Herit (2010) 11(3):239-249.

[5] Roca P. Considerations on the significance of history for the structural analysis of ancient constructions, Structural Analysis of Historical Constructions IV, Padova: University of Padova (2004).

[6] Binda, L., Saisi, A., Zanzi, L. Radar Investigation and Diagnosis of Historic Masonry, 12th International Conference Structural Faults and Repair (2008), Edinburgh 10-12/06/08, CDROM.

[7] Maierhofer, C., Leipold, S. Radar investigation of masonry structures. NDT\&E Int (2001), 34 (2):139-147.

[8] McCann, D.M., Forde, M.C. Review of NDT methods in the assessment of concrete and masonry structures. NDT\&E Int (2001), 34(2):71-84

[9] Marcari, G., Fabbrocino, G., Lourenço, P.B. Mechanical properties of tuff and calcarenite stone masonry panels under compression. In: Proceedings of the eight international masonry conference (2010). International Masonry Society; Technische Univesität Dresden., Dresden, Germany 